\title{
The cultures of archaeoastronomy and the history of science $\dagger$
}

\author{
Stephen C. McCluskey \\ Department of History, West Virginia University, Morgantown, WV 26506, USA \\ email: stephen.mccluskey@mail . wvu.edu
}

\begin{abstract}
This essay draws on the skeptical opinions that some historians of science have of archaeoastronomy, on historians' changing interpretations of proper historical method, and on their varied understandings of the nature of science to discuss how these methodological issues apply to archaeoastronomy. The essay argues that archaeoastronomical research should bear as much attention to the external context of early astronomies as it does to their internal content, suggesting specifically that insights into the origins of science can be gained by paying greater attention to the practitioners of early astronomies - to the skywatchers.
\end{abstract}

Keywords. historiography, methodology, history of science, skywatchers, ethnohistory

\section{Introduction}

When I was invited to speak on the two cultures of archaeoastronomy and the history of science, a concept reminiscent of C. P. Snow's study of the lack of communication between the two cultures of the sciences and the humanities, I thought the issue I would address would be simple. It would focus on the differing perceptions of archaeoastronomers and historians of science about each other's disciplines. From that perspective-I thoughtthe problem we had was another simple failure to communicate which could be corrected by providing 'a true perspective' on the two disciplines.

I first considered two types of sources for my discussion: one type consisted of criticisms by archaeoastronomers and historians of science of each other's disciplines, the other type consisted of examinations of archaeoastronomy by historians of science at past Oxford conferences - by Olaf Pedersen (1982) at Oxford 1, by Owen Gingerich (1989) at Oxford 2, and my own comments at Oxford 5 (McCluskey 2005) and 6 (McCluskey 2000). As I began to consider more deeply the varied opinions we historians of science have of archaeoastronomy, our varied interpretations of our own discipline, and our varied understandings of the nature of science, I soon realized that the problem was much more complex. It wasn't a tension between the perceptions and methods of the two different disciplinary traditions of archaeoastronomy, on the one hand, and of the history of science, on the other, but involved a wide range of competing models of the methods we use and the problems we address within both archaeoastronomy and the history of science.

As a consequence, I've shifted the focus of my discussion - it will address both the different cultures within the interdiscipline of archaeoastronomy and the different cultures within the discipline of the history of science. In addressing these different cultures, I will not spend much time on archaeoastronomy. The tensions within our interdiscipline are widely known and have been frequently discussed since the debates that grew out of the first Oxford Conference at Queen's College almost thirty years ago in the autumn

$\dagger$ Invited keynote lecture at Main Conference 
of 1981. The many different historiographical $\dagger$ models used by historians of science are not so familiar to archaeoastronomers, so I plan to discuss my home discipline in some detail, much as Clive Ruggles discussed the different models used by archaeologists in his Astronomy in Prehistoric Britain and Ireland (1999: 146-147).

\section{Cross-disciplinary perspectives}

To sketch out these cross-disciplinary perceptions, let's begin by considering some comments by historians of science about archaeoastronomy, and by archaeoastronomers about the history of science. In an attempt to understand the sources of these perceptions, I will then sketch out two major differences within the history of science itself: historians' differing definitions of science that would either include or exclude the traditional astronomies studied in archaeoastronomy, and differing approaches to the history of science, one focusing on the internal content of science, the other on its external context. (The external approach has much in common with the archaeoastronomers' growing concern with studying astronomies in cultures.) Finally, I will suggest how a few issues that have arisen in the history of science could lead to meaningful research questions in the study of astronomies in cultures, by considering the role of particular historical actors - of skywatchers or daykeepers - in traditional astronomies.

Speaking about archaeoastronomy, the historian of ancient Indian astronomy, David Pingree (1992: 555-556) recently said that:

"[One] form that ... Western arrogance takes is the naive assumption that other peoples

in the world not only should be like us, but actually are or were- 'were' because this particular fallacy usually affects those who study Stone Age and other preliterate cultures that have been left defenseless in the face of modern reconstructions of their thoughts... In the history of the exact sciences the scholars who perpetrate wild theories of prehistoric science call themselves archaeoastronomers."

Pingree's critique targeted particularly the kind of archaeoastronomy, which had already been criticized by archaeoastronomers in the 1980s (Ruggles 1982; 1983), that sought highly precise alignments as records of past astronomical practice. That approach is now out of fashion, so we might dismiss his comments as irrelevant to the current practice in archaeoastronomy. Yet there is still some validity in this historian's criticism of that kind of ethnocentrism in which some archaeoastronomers seek ancient astronomers in the image of modern scientists.

Interestingly, the noted archaeoastronomer Anthony Aveni recently made a similar comment about the 'presentist' concern with precise science that he saw among historians of science. In a review of the state of archaeoastronomy in the Americas, Aveni (2003: 150) described the history of astronomy as one of the disciplines that contribute to archaeoastronomy, yet he described the focus of the history of astronomy in much the same way that Pingree described the central concern of archaeoastronomy:

"History of Astronomy, a discipline well rooted in the sciences, usually engages only in the written record. It is concerned with the acquisition of precise knowledge by the ancient circum-Mediterranean cultures from which modern western science was derived."

Aveni has maintained this general view for a long time (Aveni 1981a: 1). He clarified his perspective in another paper (Aveni 1981b: S13):

"We [modern scientists] have become abstract, reductionist model builders and there are certain rules by which we play our game of science. While there is some evidence that

$\dagger$ The term historiography means both professional writing about the past and meta-historical reflections on the philosophy of history and on the nature of historical writing. In this essay, I use historiography in the meta-historical sense (Kragh 1987: 20-21). 
the Maya acquired and manipulated certain cognitive expressions the way we did, there is no indication that they took further steps along the circuitous evolutionary path we ended up following."

Aveni seems to be focusing on science as a uniquely Western, and uniquely progressive, activity. This is not what I was taught when I first studied the history of science, and I began to wonder where Tony got that idea. It turns out that he got if from some historians of science. You see-historians of science don't agree about their discipline any more than archaeologists or archaeoastronomers do about theirs.

A parallel to Aveni's approach can be found in a valuable essay (Gingerich 1989) on the role of archaeoastronomy in the history of astronomy that Owen Gingerich presented in 1986 at Oxford 2 in Mérida, Mexico. Gingerich is a historian of the astronomy of the Scientific Revolution of the 16th and 17th centuries. Consequently, he was concerned with two questions that engage many historians of the Scientific Revolution. First, 'Why did the Scientific Revolution take place in Western Europe?', and second, 'Why didn't a scientific revolution take place at other times and in other cultures?' (Cohen 1994: 378-384).

Addressing these questions, Gingerich (1989: 38) asserted that: "Modern science is a uniquely Western phenomenon that has arisen only once on our planet." Note carefully, Gingerich is not talking here about science in general, but only about modern science. Few would disagree with his idea that the Scientific Revolution emerged only once with the discoveries of Copernicus and Kepler, of Galileo and Newton; and with the emergence of scientific institutions like the Accademia dei Lincei (Rome, 1603), the Accademia del Cimento (Florence, 1657), the Royal Society of London (1660), and the Académie des sciences (Paris, 1666). That kind of event was never repeated anywhere in the world.

However, as Gingerich continued his discussion, his topic shifted subtly from a consideration of modern science to a consideration of science in general, without any qualifying adjectives. He noted (1989: 39) how those early archaeoastronomers who studied megalithic sites

"were well rooted within Western science and engineering, and they firmly believed

that their interdisciplinary field had something to say ... about the roots of science itself."

Gingerich thought this approach would not be productive, but he did suggest that archaeoastronomy might offer some insight into another related question (1989: 40): "whether science arises inevitably and in a form similar to our own." He concluded (1989: 41) that despite the sophistication of Maya astronomy, "The apparent dead end that Mayan mathematical culture reached seems ... a case for the non-origin of science." In Gingerich's judgment, Maya mathematical astronomy had not reached the level of real science - which he tacitly equated with the kind of modern science that emerged in Western Europe in the 17th century.

Gingerich is part of a well established historiographical tradition that builds its historical narrative around the emergence of Western Science. The earliest historians of science, writing in the 18th century, were scientists, and they were concerned with those historical developments that ultimately contributed to the present state and future progress of their disciplines. From this perspective the history of science became the history of scientific progress (Kragh 1987: 3-9).

\section{What is (modern) science?}

The most articulate modern exponent of this approach was the Belgian-American historian of science, George Sarton. Sarton established the leading journal in the history of science, Isis, and is often identified as the founder of the modern study of the history 
of science. Sarton became a strong advocate of the history of science, especially for its relevance for modern scientific research. His interpretation of the discipline grew out of the positivist philosophy of Auguste Comte, who took mathematics and physics as the model of positive knowledge (Kragh 1987: 17-19). Sarton (1936: 5) set out his understanding of the place of science in history with all the apparent rigor of a geometrical proof:

- "Definition. Science is systematized positive knowledge, or what has been taken as such at different ages and in different places.

- Theorem. The acquisition and systematization of positive knowledge are the only human activities which are truly cumulative and progressive.

- Corollary. The history of science is the only history which can illustrate the progress of mankind."

In his definition, Sarton sought to draw a sharp line of demarcation between science and all other human activities. Earlier he had written that while the saints and artists of today may be no better or worse than those of antiquity, the scientists of today, while not more intelligent, have knowledge that is both "more extensive and more accurate". Consequently, "our knowledge of the world and of ourselves is deeper, more precise, and more certain" (Sarton 1927: vol. 1, 4-5). This kind of progress in positive knowledge identified, for Sarton, the true historical significance of science and of its history.

Sarton's definition was not widely accepted by historians of science. When I first studied the history of science in the 1960s, Sarton's positivism was presented as a lesson of how not to study the history of science. Instead, other understandings of the nature of science, much more open-ended than Sarton's, were coming into favor among historians of science.

The earliest expression I know of this tradition appears in the physicist/historian William Dampier-Wetham's article on "Science" in the 1911 edition of the Encyclopadia Britannica (Dampier-Wetham 2011):

"Science may be defined as ordered knowledge of natural phenomena and of the relations between them."

Unlike Sarton, Dampier-Wetham did not restrict his definition to systematized positive knowledge, but only to organized knowledge. He did, however, restrict the scope of science to knowledge of natural phenomena - a restriction that Sarton had not made explicit.

Recently Nathan Sivin (who spoke on Chinese Astronomy at Oxford 2) and the historian of Greek Science, Sir Geoffrey Lloyd (Lloyd \& Sivin 2002: 4) seized upon subject matter as the mark of science, while explicitly rejecting modern science as the norm:

"The mark of science ... lies in the aims of the investigation and the subject matterthe bid to comprehend aspects of the physical world - not in the degree to which either the methods or the results tally with those of later inquiries, let alone modern science."

Further modifications to the Britannica definition were made by the historian of medieval science, Marshall Clagett, in his Greek Science in Antiquity (1955: 4) and more provocatively by Pingree (1992: 559):

"Science is a systematic explanation of perceived or imaginary phenomena, or else is based on such an explanation. Mathematics finds a place in science only as one of the symbolical languages in which scientific explanations may be expressed."

Pingree's elimination of truth or falsehood from his definition was deliberate, since as he said, "explanations of phenomena are never complete and can never be proved to be 'true'" (1992: 559). His further expansion of the definition of science to encompass the study of imaginary phenomena would certainly have been beyond the pale for Sarton, who rejected the study of superstition and magic, which he considered to be "unprogressive and conservative" (1927: 19). 
We might ask why a historian of science like Pingree, with his broad definition of science, would have expressed such a critical opinion of archaeoastronomy as I have discussed previously. The answer seems to be twofold. Pingree did not see the early generation of archaeoastronomical research to be either convincing or culturally appropriate. From his study of pre-literate cultures, he saw no evidence of an interest in the study of "the stars before the end of the third millennium B.C." (1992: 556) nor was there evidence of any cultural motive for such an interest. With the concern for motives for the study of astronomy, we have moved from a concern with the content of early science to its cultural context, and so we must now address the place of the external context of science in the historiography of science.

\section{Internal vs. external history}

The earliest histories of science focused on the development of scientific ideas - occasionally venturing beyond purely scientific ideas to consider their interaction with contemporary philosophical or theological ideas. In its most extreme form, this 'internal' history of science can become the history of disembodied scientific ideas, almost ignoring the real historical agents who developed those ideas. Internal history of science has been challenged since the 1930s, as historians increasingly came to consider new questions dealing with the roles of a wide range of 'external' factors (such as economic interests, scientific institutions and professions, religious movements, and the like) on the development of science (Cohen 1994: 198-200, 342-346, 374-376, 502-505).

Perhaps the best indicator of this shift in the history of science would be a quick glance at a run of the thematic volumes of the other journal founded by Sarton, Osiris. Each of its volumes addresses a specific topic in the history of science, and these topics have generally been drawn from the external history of science, ranging from science and religion to science and politics. Sarton's positivist history of scientific ideas is rarely seen in the pages of the journal he founded.

Paradoxically, while the internal history of science was initiated by those historians of science who focused on modern science, the internal approach is much more enduring in the history of early science - just as it is in archaeoastronomical research. I suggest two simple reasons for this. The first is that the historian of modern science can draw on a general understanding of the principles of modern science to analyze its history; the second is that there is little need for the historian of modern science to teach those sciences that are already taught by the scientists. The historian of the sciences of other times and cultures faces a very different situation. The mastery of the internal concepts of ancient astronomy, such as the numerical relations among planetary periodicities, the geometry of Ptolemaic epicycles, the mathematics of Babylonian functions for the prediction of planetary phenomena, or the Aristotelian physics of the heavens, requires significant study in its own right. Research into early astronomies requires that the historian interpret the surviving evidence in order to unravel the structure and meaning of other astronomical systems. Teaching about early astronomies requires the historian to pass on these unfamiliar systems to his students - for they will not learn them in their studies of modern science.

Thus, internal history of science still has an important role to play. There now seems to be an emerging consensus that while external considerations of context are essential elements for a complete historical discussion of the science of a particular time and place, this external discussion cannot take place in isolation from an understanding of the internal content of a culture's science (Cohen 1994: 199-200). 


\subsection{Externalist archaeoastronomy}

Some years ago I briefly commented on the role of such external factors in archaeoastronomy at Oxford 5 in Santa Fe, proposing that it would be useful to consider four different aspects of science. The first three science as a process of investigation, science as a body of knowledge, and science as a set of procedures - were clearly internal in nature. The fourth aspect finally touched on some external elements of science: the scientific community and the institutions in which scientists work (McCluskey 2005: 71). I have increasingly come to realize that a consideration of the scientific community is as important an object of study for archaeoastronomers as it is for historians of science.

Two examples of the external approach bridging the history of science and archaeoastronomy were presented in 1990 at Oxford 3 in Saint Andrews by David King and myself. In a pair of strikingly similar papers, King (1993) discussed the roles of practical astronomies in medieval Islam, while I (McCluskey 1993) addressed the similar roles of such astronomies in early medieval Europe. Both of us saw astronomy being practiced for external religious motives - to determine the time of prayer, to regulate the calendar, and to determine the proper direction to pray. King, who in other publications had examined the mathematical astronomy of the Islamic world, distinguished the traditional techniques of folk astronomy employed for these religious purposes from the traditions of navigational and mathematical astronomy. Significantly, while both of our discussions focused on this religiously motivated astronomical practice, neither of us spent much time discussing the individuals or groups who had practiced these astronomies.

King has subsequently done much to fill this gap, most notably in a paper "On the Role of the Muezzin and Muwaqqit in Medieval Islamic Society" (King 1996). There, King identified a particular class of professional timekeeper, the muwaqqit, responsible for many of the astronomical functions that he had described in his Oxford 3 paper. Muwaqqits - who are first mentioned in the 13th century - were salaried officials of larger mosques whose chief responsibility was to advise the muezzin concerning the proper times of prayer. In sum, we have professional practitioners of the science of astronomy - in the broader sense of the word 'science'. Although their professional responsibility did not extend to astronomical research, their position offered interested muwaqqits the time and the opportunity to engage in further astronomical study (Sabra 1996: 25).

It is not clear whether there were enough muwaqqits at any given mosque to constitute a community of experts in astronomical timekeeping. Late financial and historical records indicate that some of the larger mosques had several muezzins and muwaqqits; one late source indicates that in the 17th century the Umayyad Mosque in Damascus had 75 muezzins (King 1996: 302-303). At the mosques of Damascus and Cairo, the office of muwaqqit did have sufficient continuity to allow the development of local traditions of astronomical scholarship (ibid.: 286-287, 308, 309). Muwaqqits sometimes succeeded to the post within a family (ibid.: 298-299, 313-317): for example, three generations from the same family served in the 13th and 14th centuries at the Mosque of 'Amr in Fustat (Old Cairo).

One exceptional 14th-century muwaqqit, Ibn al-Shātir, made noteworthy accomplishments in two areas: he constructed an elaborate horizontal sundial for the Umayyad Mosque in Damascus which indicated the hours in relation to the times of prayer, and he developed a geometrical alternative to the Ptolemaic astronomical model for the motion of the planets (King 1996: 306). Ibn al-Shātir was an exception, and from the perspective of a historian who focuses on the path that leads to modern science, the office of muwaqqit may not seem so important (Bergren 1996: 275-276). However, if we are concerned with identifying the opportunities for and the locales of the practice of science in 
a given culture - in a given time and place - then the muwaqqit, and similar timekeeping offices in other cultures, take on a crucial importance.

It seems to me that it would be wise if we who study the astronomies of different cultures would move from an exclusive focus on the ideas and practices of those astronomies to a broader investigation of what role individual timekeepers like Ibn al-Shātir, or specific offices like the muwaqqit, play in those astronomies. I would now like to look at how archaeoastronomical research seems to be undergoing such a methodological shift.

\section{Skywatchers}

Such a shift seems appropriate. We have increasingly come to understand the internal techniques and concepts of the astronomies we study, but many unanswered questions remain concerning the external circumstances of these astronomies. Most especially, we know little about the practitioners of these astronomies - in a word, the skywatchers. Some questions would address their training, their roles in society, how they are supported, and even their motives for developing specific aspects of their astronomical systems and techniques.

Thirty years ago Tony Aveni wrote a groundbreaking book on the astronomies of Mesoamerica, entitled Skywatchers of Ancient Mexico (Aveni 1980; revised and updated as Aveni 2001). The title of the book suggests that we might find some details about these individuals, but in fact the book is much more about skywatching than about skywatchers; it provides detailed discussions of the internal content of the astronomies of Mesoamerica and of other parts of the Americas. We find masterful discussions of observation techniques, of alignments of structures, of cosmological models, of the Mesoamerican fascination with numerological concepts and of the expression of those concepts in their calendars and astronomical codices. Strangely underrepresented, however, given the title of the book, are the skywatchers themselves.

\subsection{Ethnohistorical evidence}

Perhaps we should not be too surprised, given the limitations of the sources on Mesoamerican astronomers. Aveni cites the colonial Spanish Friar Juan de Torquemada's description of Nezahualpilli, who reigned as King of Texcoco from 1462-1515. He was described as a learned astronomer who studied the motions of the celestial bodies, watched the stars at night from the roof of his palace, and discussed them with other knowledgeable persons (Aveni 2001: 16-17).

Elsewhere Aveni quotes Bishop Diego de Landa on the leading astronomer-priests of colonial Yucatan, the ah kins, or daykeepers (literally the person of the Sun or of the day) who taught "the computation of the years, the administration of the sacraments, the fateful days and seasons, their methods of devotion and their prophecies" (Aveni 2001: 127-128). Here we have a clear indication of the primary functions of these professional astronomical diviners, yet by digging deeper into Landa's description we can gain a richer picture of the social position and breadth of scholarship of the ah kin.

Landa notes the influential status of the ah kin, for "They taught the sons of the other priests and the second sons of the lords who brought them for this purpose from their infancy, if they saw that they had an inclination for this profession". Typically, the ah kin's "sons or his nearest relatives succeeded him in his office" (Landa 1941 [1566]: 27). Ah kin who were important enough to appear in the historical record are reported to have taught their art to their sons-in-law or stepsons (ibid.: 40, 43). We see signs here of a tradition of astronomical expertise being passed on within a family, not unlike the pattern that King identified among the Islamic muwaqqits. 
However, they were not just experts in astronomy, the calendar, and divination; the ah kin also taught and studied "cures for diseases, their antiquities [i.e., history], and how to read and write" (Landa 1941: 28). Although these men knew astronomy and its related calculations, they were not narrowly professional astronomical specialists.

Moving from colonial historical records to the accounts of modern ethnographers, there are occasional reports of contact with practicing skywatchers, but again these accounts primarily tell us of skywatching practice (Aveni 2001: 44-45). Aveni's most detailed ethnographic account of modern skywatchers draws on the work of Barbara Tedlock, which I will now address.

\subsection{Ethnographic studies}

Tedlock is widely known for her ethnographic fieldwork among the contemporary Quiché Maya of Momostenango, in Guatemala (1992). There she and her husband underwent a period of training and initiation to become daykeepers (who seem more like the ordinary priests of Landa's description than the ah kin who trained the priests and the children of nobility). From this deep immersion into the life of daykeepers, Tedlock presents a rich picture of the roles that these traditional figures play in the political and social hierarchy of a modern - yet traditional-Maya community.

More significantly, she describes the training and initiation of both the ordinary daykeepers and of the priest-shamans or 'mother-fathers' who are more senior in the traditional hierarchy, and serve as headmen and priest-shamans to their own patrilineage (Tedlock 1992: 46-82). The ordinary daykeepers know the principles of calendrical divination and the regular pattern of calendric ceremonies at specific shrines, but some undergo further training as midwives, bone setters, singers, matchmakers, and spiritualists (ibid.: 73-74). The more senior priest-shamans form a corporate hierarchy that provides "a bridge between religious and governmental duties" in the community (ibid.: 35-37).

Tedlock's rich discussion of the astronomical lore of Momostenango, however, is not closely tied to the practices of the daykeepers. Yet she does associate certain ritual practices of the senior 'mother-fathers of the town' with the opportunity for observations that could coordinate lunar time reckoning with the 260-day calendric cycle and the 365day solar year (Tedlock 1992: 192-195). This connection of ritual practice with possible astronomical observations by senior experts in the calendar is reminiscent of the role of the colonial ah kin, yet in none of these examples do we see evidence of a class of narrowly specialized astronomical practitioners.

\section{Investigating astronomical practitioners}

Signs of astronomical specialists do emerge in recent studies of the early history of Maya skywatchers, which use Maya inscriptions as their source material. Gerardo Aldana, having studied as a historian of science at Harvard under Owen Gingerich, drew historical inferences by relating detailed internal analysis of the astronomical content of Maya inscriptions to contemporary external political events. In a paper at Oxford 7, Aldana (2006: 248-249) considered the historical significance of changing patterns of uniformity and non-uniformity in the computed lunar ages on Maya inscriptions. In some of the early inscriptions from Mutul (modern Tikal), he found a pattern where, despite frequent changes of rulers, the method of recording lunar ages remained uniform. He postulated that this uniformity suggested that the counting of moons was not carried out by the ruler or by one of his courtiers, but was the task of a stable astronomical community that was not tied too closely to the political structure. In sum, he saw evidence in the data for the existence of a professional Maya astronomical community at a particular time and place-6th-century Mutul. 
In a similar study of 7th-century Palenque, Aldana identified astronomical practices that were more closely tied to the court and its politics. He addressed the creative activity of a community of scholars at the time of the rise of Janaab' Pakal of Palenque and his successors, especially his son, Kan B'ahlam. Further evidence of this astronomical community, besides their astronomical creativity, is provided by archaeological evidence of a non-royal elite housing complex and inscriptions, which Aldana proposes named these scholars (2007: 123-124). These court astronomers invented a new mathematical technique - the 819-day count - which they used to compute intervals incorporating significant astronomical and calendric periods that connected historical events in the reigns of their patrons to their mythological antecedents thousands of years in the past. These astronumerologically significant contrived numbers provided legitimization for the new dynasty of Janaab' Pakal by connecting it to the distant mythological past.

Aldana's ability to draw plausible pictures of astronomical communities from fragmentary evidence - that is, from dated astronomical records and from our limited knowledge of Maya history - reminds us that there are often unexpected ways to uncover the external context of the astronomies we study. And that context remains important, for as Aldana reminded us at Oxford 7, the practice of "science is never a 'pure' endeavorthere are always political, social, and ideological undercurrents visible within scientific activity" (2006: 237).

These examples show us the kind of insights that we can obtain into individual and groups of astronomical practitioners from limited evidence - and consequently of the kind of evidence we should be alert to in our own research. To give an example of how this might be done, I took a second look at the owner of a Winnebago calendar stick which had been discussed in a pair of papers presented at Oxford 2 by Alexander Marshack (1989) and Breen Murray (1989). Both authors provide detailed internal analyses of the astronomical content of this artifact, and Marshack credits its owner, a Winnebago warrior named Tshi-zun-hau-kau, with devising an "accurate, functional, non-arithmetic observational lunar-solar intercalary notation" (1985: 48).

Whether his calendar stick was his own invention, as his 19th-century biographer indicates (McKenney \& Hall 1936 [1836-44]: vol. 3, 409-410), or was developed within "an already evolved tradition of" making similar calendar sticks, as Marshack's study suggests (1989: 308), is of little importance here. What seems significant from the perspective of the external history of science is that Tshi-zun-hau-kau is clearly an example of an astronomical timekeeper who, like the others we have considered, had the opportunity to develop astronomical techniques and devices.

We might ask, then, what his 19th-century biography (McKenney \& Hall 1936 [183644]: vol. 3, 405-410) and the accompanying portrait (Fig. 1) can tell us about him, and by inference, about such timekeepers in general. First, and perhaps most importantly, he was a leader of some importance among his people; he wore a presidential treaty medal and was one of a group invited to visit Washington in 1828, where his portrait was painted. Secondly, he was noted for his ability as a warrior and hunter, skills reflected in the tomahawk he carries and his name, which is translated as 'He who runs with the deer'. Third he had a reputation as a healer, not as a professional but as one who "practiced the art when it suited his convenience, and had the reputation of possessing the gift". Again, the portrait hints at this, as his calendar stick is decorated with blossoms of Indian Paint Brush, a plant known for its medicinal properties (Moerman 2003).

The picture we get by applying questions drawn from the external history of science to archaeoastronomical investigations is that astronomical practitioners tended to be socially and politically important members of their communities; they were seldom narrow astronomical specialists but were more often widely educated in a number of 
Figure 1. Tshi-zun-hau-kau. Portrait by Henry Inman at the De Young Museum, San Francisco. Photograph by Molly Eyres, used by permission.

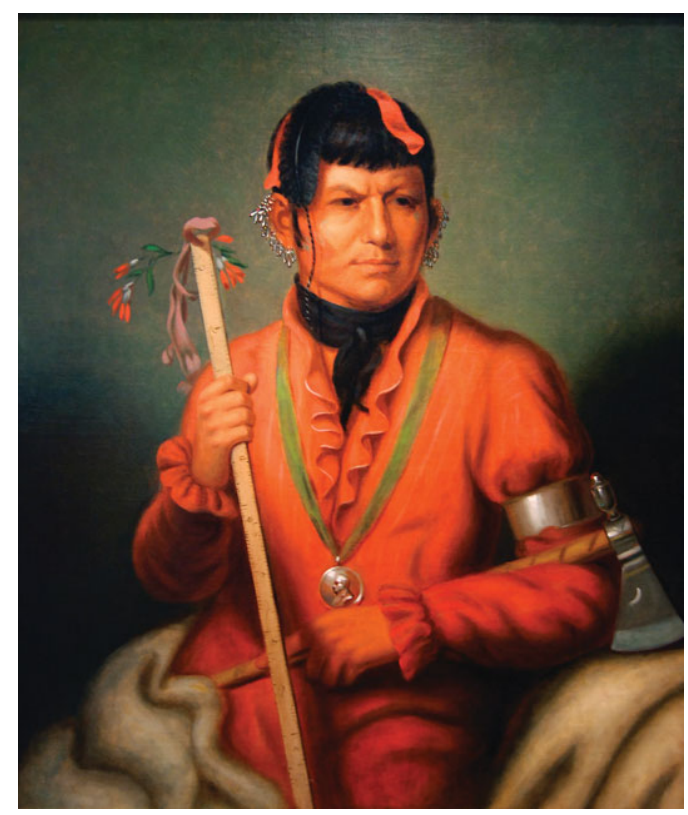

scholarly traditions, encompassing what we could call medicine and history. Further archaeoastronomical investigation of astronomical practitioners in other cultures can be an important contribution to our understanding of how and why astronomy is practiced in different cultures, and hence to our understanding of the origins of science.

\section{Acknowledgements}

I am grateful to Gerardo Aldana, Anthony Aveni, Owen Gingerich, and David King for commenting on an earlier version of this paper.

\section{References}

Aldana, G. 2006, Lunar alliances: shedding light on conflicting Classic Maya theories of hegemony. In Bostwick, T. W. \& Bates, B. (eds), Viewing the Sky Through Past and Present Cultures, Anthropological Papers 15, Pueblo Grande Museum, Phoenix, pp. 237-258.

Aldana, G. 2007, The Apotheosis of Janaab' Pakal: Science, History, and Religion at Classic Maya Palenque, University Press of Colorado, Boulder.

Aveni, A. F. 1980, Skywatchers of Ancient Mexico, University of Texas Press, Austin.

Aveni, A. F. 1981a, Archaeoastronomy. Advances in Archaeological Method and Theory 4, 1-77.

Aveni, A. F. 1981b, Archaeoastronomy in the Maya region: a review of the past decade. Archaeoastronomy no. 3 (supplement to Journal for the History of Astronomy 12), S1-S16.

Aveni, A. F. 2001, Skywatchers, University of Texas Press, Austin.

Aveni, A. F. 2003, Archaeoastronomy in the ancient Americas. Journal of Archaeological Research 11, 149-191.

Berggren, J. L. 1996, Islamic acquisition of the foreign sciences: a cultural perspective. In F. J. Ragep, S. P. Ragep \& S. Livesey (eds), Tradition, Transmission, Transformation: Proceedings of Two Conferences on Pre-modern Science held at the University of Oklahoma, E. J. Brill, Leiden, pp. 263-283.

Clagett, M. 1955, Greek Science in Antiquity, Abelard-Schuman, New York.

Cohen, H. F. 1994, The Scientific Revolution: a Historiographical Inquiry, University of Chicago Press, Chicago.

Dampier-Wetham, W. C. 1911, Science. In Encyclop cdia Britannica (11th edn), Encyclopedia Brittanica, Inc., New York. 
Gingerich, O. 1989, Reflections on the role of archaeoastronomy in the history of astronomy. In A. F. Aveni (ed.), World Archaeoastronomy, Cambridge University Press, Cambridge, pp. $38-44$.

King, D. A. 1993, Folk astronomy in the service of religion: the case of Islam. In C. L. N. Ruggles \& N. J. Saunders (eds), Astronomies and Cultures, University Press of Colorado, Niwot, pp. 124-138.

King, D. A. 1996, On the role of the muezzin and muwaqqit in medieval Islamic society. In F. J. Ragep, S. P. Ragep \& S. Livesey (eds), Tradition, Transmission, Transformation: Proceedings of Two Conferences on Pre-modern Science held at the University of Oklahoma, E. J. Brill, Leiden, pp. 285-346.

Kragh, H. 1987, An Introduction to the Historiography of Science, Cambridge University Press, Cambridge.

Landa, Diego de 1941 [1566], Landa's Relación de las Cosas de Yucatan, a Translation, transl. \& ed. A. M. Tozzer, Papers of the Peabody Museum of American Archaeology and Ethnology 18, Peabody Museum, Cambridge MA.

Lloyd, G. \& Sivin, N. 2002, The Way and the Word: Science and Medicine in Early China and Greece, Yale University Press, New Haven.

McCluskey, S. C. 1993, Astronomies and rituals at the dawn of the Middle Ages. In C. L. N. Ruggles \& N. J. Saunders (eds), Astronomies and Cultures, University Press of Colorado, Niwot, pp. 100-123.

McCluskey, S. C. 2000, The inconstant moon: lunar astronomies in different cultures. Archaeoastronomy: the Journal of Astronomy in Culture 15, 14-31.

McCluskey, S. C. 2005, Different astronomies, different cultures, and the question of cultural relativism. In J. W. Fountain \& R. M. Sinclair (eds), Current Studies in Archaeoastronomy: Conversations Across Time and Space, Carolina Academic Press, Durham, NC, pp. 69-79.

McKenney, T. L. \& Hall, J. 1936 [1836-44], History of the Indian Tribes of North America, with Biographical Sketches and Anecdotes of the Principal Chiefs (3 vols), John Grant, Edinburgh.

Marshack, A. 1985, A lunar-solar year calendar stick from North America. American Antiquity $50,27-51$.

Marshack, A. 1989, North American Indian calendar sticks: the evidence for a widely distributed tradition. In A. F. Aveni (ed.), World Archaeoastronomy, Cambridge University Press, Cambridge, pp. 308-324.

Moerman, D. 2003, Native American Ethnobotany: A database of plants used as drugs, foods, dyes, fibers, and more, by native peoples of North America. http://herb.umd.umich.edu/.

Murray, W. B. 1989, A re-examination of the Winnebago calendar stick. In A. F. Aveni (ed.), World Archaeoastronomy, Cambridge University Press, Cambridge, pp. 325-330.

Pedersen, O. 1982, The present position of archaeo-astronomy. In D. C. Heggie (ed.), Archaeoastronomy in the Old World, Cambridge University Press, Cambridge, pp. 265-274.

Pingree, D. 1992, Hellenophilia versus the history of science. Isis 83, 554-563.

Ruggles, C. L. N. 1982, A reassessment of the high precision megalithic lunar sightlines, 1: backsights, indicators, and the archaeological status of the sightlines. Archaeoastronomy no. 4 (supplement to Journal for the History of Astronomy 13), S21-S40.

Ruggles, C. L. N. 1983, A reassessment of the high precision megalithic lunar sightlines, 2: foresights and the problem of selection. Archaeoastronomy no. 5 (supplement to Journal for the History of Astronomy 14), S1-S36.

Ruggles, C. L. N. 1999, Astronomy in Prehistoric Britain and Ireland, Yale University Press, New Haven.

Sabra, A. I. 1996, The appropriation and subsequent naturalization of Greek science in Medieval Islam: a preliminary statement. In F. J. Ragep, S. P. Ragep \& S. Livesey (eds), Tradition, Transmission, Transformation: Proceedings of Two Conferences on Pre-modern Science held at the University of Oklahoma, E. J. Brill, Leiden, pp. 3-27.

Sarton, G. 1927, An Introduction to the History of Science, Carnegie Institute of Washington Publication 376 (3 vols. in 5), Carnegie Institute, Washington DC.

Sarton, G. 1936, The Study of the History of Science, Harvard University Press, Cambridge.

Tedlock, B. 1992, Time and the Highland Maya (revised edn.), University of New Mexico Press, Albuquerque. 